\title{
Short communication: Milk ELISA status for bovine leukosis virus infection is not associated with milk production in dairy cows
}

\author{
U. S. Sorge,${ }^{\star 1}$ K. Lissemore, $†$ R. Cantin, $\neq$ and D. F. Kelton $†$ \\ *Department of Veterinary Population Medicine, University of Minnesota, St. Paul 55108 \\ †Department of Population Medicine, University of Guelph, Guelph N1G 2W1, Ontario, Canada \\ $\ddagger$ CanWest DHI, Guelph N1K 1E5, Ontario, Canada
}

\section{ABSTRACT}

The objective of this study was to assess whether the milk ELISA status for antibodies against bovine leukemia virus was associated with 305-d milk production in Canadian dairy cattle. Test results and test-day production data from 19,785 dairy cows were available for analysis. A linear mixed model was used with the estimated 305-d milk production as the outcome and lactation number, somatic cell count, calving season, days in milk, and breed as fixed effects. Herd nested in province was included as random effect. In conclusion, bovine leukemia virus antibody milk ELISA status was not associated with milk production.

Key words: enzootic bovine leukosis, ELISA, milk production, dairy cows

\section{Short Communication}

Enzootic bovine leukosis (EBL) is a viral disease of cattle caused by the bovine leukemia virus (BLV). A recent Canadian study estimated that, in Alberta, approximately $27 \%$ of dairy cows and $87 \%$ of herds were test positive for EBL (Scott et al., 2006). For Manitoba, a seroprevalence of 60.8 and $10.3 \%$ was reported for dairy and beef cows, respectively (VanLeeuwen et al., 2006). In dairy herds in the United States, more than $82 \%$ have a positive bulk tank sample for EBL (APHIS-USDA, 2008). Although the infection is common, relatively few infected adult cattle develop clinical signs of the disease (Pollari et al., 1992), which are most commonly lymphosarcoma and less commonly leukemia (Reed, 1981).

Nevertheless, the disease is of economic importance, because trade restrictions apply to the export of cattle from infected herds and countries, and because EBL has been associated with production losses during the later stages of infection (Reed, 1981). However contradictory

Received March 4, 2011.

Accepted June 22, 2011.

${ }^{1}$ Corresponding author: sorge@umn.edu reports exist about the association between subclinical BLV infection and milk production in cattle. One study suggested that, depending on the cow's age, EBL is associated with a 10 to $17 \%$ increased FCM production in cows that were seropositive or had lymphosarcoma, compared with seronegative cows (Pollari et al., 1992). On the other hand, another study associated BLV infection with a $3 \%$ decreased milk production per cow compared with cows from seronegative herds (Ott et al., 2003). Other studies were unable to establish an association (Huber et al., 1981; Brenner et al., 1989). The objective of this study was to assess whether the milk ELISA status for BLV infection is associated with milk production.

CanWest Dairy Herd Improvement has been offering a milk ELISA test for leukosis to its members since the spring of 2007. The milk ELISA (Antel BioSystems Inc., Lansing, MI; Antel BioSystems Inc., 2007) has a reported sensitivity of $98.1 \%$ and specificity of $100 \%$ compared with a serum ELISA (IDEXX Laboratories Inc., Portland, ME). For this study, the results of 19,785 EBL milk ELISA from individual cows, as well as the cows' production records from the test-day and current lactation were available. The cows came from 258 herds in Ontario and western Canada. Between 1 and 555 EBL milk ELISA were conducted on each of these farms between April 2, 2007 and December 20, 2009. Some cows $(\mathrm{n}=1,629 ; 8.2 \%)$ were tested multiple times with the milk ELISA. No information was available about the producer's reasons for the testing of the cows, results of other EBL tests, clinical health status of the tested cows, or whether all cows of the milking herd were tested.

The statistical analysis was conducted in SAS 9.2 (SAS Institute Inc., Cary, NC) and the significance level was set at $\alpha=0.05$. A linear mixed model (PROC MIXED) was used to investigate the association between a cow's EBL milk ELISA status and her estimated 305-d milk production (M305, in kg). Negative and suspect milk ELISA results were combined and considered test negative. The data from cows tested earlier than 60 DIM were excluded $(\mathrm{n}=4,232)$, because 
the M305 is overestimated during the early stages of lactation (Quist et al., 2007). Cows of the breeds Canadienne $(\mathrm{n}=1)$ and cross-breeds $(\mathrm{n}=3)$ were excluded from the analysis, because too few ELISA results were available and no within-breed comparison groups were available.

Because none of the cows tested more than once changed in their test result at the subsequent test, and most cows were only tested once, the first EBL milk ELISA per cow was used for this analysis. Stage of lactation was expressed as DIM in 30-d intervals. Cows longer than 305 DIM were combined into 1 category at 305 d. Besides the EBL milk ELISA result, the model initially included the following covariates as fixed effects: calving season, breed of the cow, DIM, DIM ${ }^{2}$, lactation number, and linear SCC. Herd nested in province was included as a random effect. The EBL milk ELISA result (positive vs. negative) was forced into the model; other fixed effects were removed from the model through backward elimination.

The assumptions of linear regressions (normality, homoscedasticity, and linearity) were assessed visually through residual plots, as well as by using descriptive statistics (proc univariate).

In the end, the ELISA results of 13,664 cows were used for the analysis. They included cattle of Ayrshire $(\mathrm{n}=73)$, Brown Swiss $(\mathrm{n}=118)$, Guernsey $(\mathrm{n}=7)$, Holstein $(\mathrm{n}=13,046)$, Jersey $(\mathrm{n}=353)$, and Milking Shorthorn $(\mathrm{n}=67)$ breed. There were 8,901 $(65 \%)$ testnegative cows and 4,763 (35\%) test-positive cows. The majority of herds in the final model were from Ontario $(\mathrm{n}=159,62 \%)$, followed by Alberta $(\mathrm{n}=55,22 \%)$, British Columbia $(\mathrm{n}=20,8 \%)$. Manitoba $(\mathrm{n}=13$, $5 \%)$, and Saskatchewan $(\mathrm{n}=7,3 \%)$.

As expected, calving season, SCC, DIM, and lactation number were associated with M305 (Table 1). The average M305 did not differ between EBL test-positive and test-negative cows $(P=0.8143)$ in this crosssectional study. This result did not change when the model was recreated, including cows with $\leq 60$ DIM ( $P$ $=0.3915)$. These findings are contrary to the results of Ott et al. (2003), who observed significant differences in milk production of seropositive herds compared with seronegative herds. However, that study used herd-average variables as covariates, such as categorized bulk tank SCC, which might help to explain the differences between these 2 studies. In addition, we were unable to compute the leukosis prevalence in the current data set with the data available, as our samples were not selected randomly, nor were all cows in each herd tested in this study.

Our observations are in agreement with other studies (Huber et al., 1981; Brenner et al., 1989; Da et al., 1993), who also compared seropositive to sero- negative cows. However, Da et al. (1993) also found that once the animals became lymphocytotic, their milk production decreased significantly. Interestingly, non-lymphocytotic seropositive animals had high milk production in higher lactations (Pollari et al., 1992; Da et al., 1993). Given the selection pressure applied to dairy cattle for high milk yield, it is not surprising that Pollari et al. (1992) observed that seropositive, nonlymphocytotic cows were culled at an older age than seronegative cattle.

Because we linked the first available EBL milk ELISA with the estimated M305 production at the same test day, culling based on EBL test status had not occurred yet, minimizing the bias that might have been introduced by selective culling based on EBL milk ELISA status. The authors acknowledge that this study classified cows on a single EBL milk ELISA result, which could have masked any effect differences in milk production effect at different stages of the disease. Whether infected, lymphocytotic cows were culled for low production before being subjected to an EBL milk ELISA test is impossible to determine based on the limitations of the data available, but could have affected the results. Similarly, if individual cows were tested for EBL because they were suspected of being infected, an inherent selection bias may have existed in at least some of the data points. Unfortunately, we

Table 1. Results of the linear mixed model, assessing the association between enzootic bovine leukosis milk ELISA results and the estimated 305-d milk production $(\mathrm{kg})$ after accounting for calving season, DIM ${ }^{1}$ in 30-d increments, breed, linear SCC, lactation number, and province

\begin{tabular}{lccr}
\hline Parameter & Estimate & SEM & $P$-value \\
\hline $\begin{array}{l}\text { Intercept } \\
\text { Leukosis milk ELISA result }\end{array}$ & $9,174.8$ & 244.9 & $<0.0001$ \\
$\quad$ Positive & 6.9 & 26.7 & 0.8143 \\
$\quad$ Negative & Referent & & \\
Calving season & & & \\
Spring & -98.3 & 37.4 & 0.0085 \\
Summer & -325.7 & 36.0 & $<0.0001$ \\
Fall & -57.3 & 34.7 & 0.0984 \\
Winter & Referent & & \\
SCC & -108.7 & 10.8 & $<0.0001$ \\
DIM & 72.6 & 3.9 & $<0.0001$ \\
Lactation & & & \\
1 & $-2,128.3$ & 46.7 & $<0.0001$ \\
2 & -533.7 & 48.5 & $<0.0001$ \\
3 & 72.4 & 51.2 & 0.1570 \\
4 & 229.9 & 58.2 & $<0.0001$ \\
B5 & Referent & & \\
Breed & & & \\
Ayrshire & -488.1 & 452.5 & 0.2807 \\
Brown Swiss & 982.4 & 281.3 & 0.0005 \\
Guernsey & $-1,489.2$ & 617.3 & 0.0159 \\
Holstein & $1,853.9$ & 222.6 & $<0.0001$ \\
Jersey & $-1,395.1$ & 255.0 & $<0.0001$ \\
Milking Shorthorn & Referent & & \\
\hline Does incte & & & \\
\hline
\end{tabular}

${ }^{1}$ Does not include $<60$ DIM.

${ }^{2}$ Herd was included as random effect. 
do not know why producers decided to test individual animals or their herds, nor do we know the cows' health history or which animals may have been misclassified by the imperfect test; therefore, we can only speculate on the effect these might have had on the results of this analysis. However, given the size of this data set, it seems highly unlikely that any of these potential biases would have changed the conclusions. Based on the data available, the EBL milk ELISA status of dairy cows was not associated with the estimated M305 milk production in the test lactation.

\section{REFERENCES}

Antel BioSystems Inc. 2007. AntelBio leukosis milk ELISA: Review of technical studies. Accessed Oct. 8, 2010. www.antelbio.com/Testing/Leukosis\%20Milk\%20Review\%20for\%20web.pdf.

APHIS-USDA. 2008. Bovine leukosis virus (BLV) on U.S. dairy operations, 2007. Accessed Aug. 4, 2011. http://www.aphis.usda.gov/ animal_health/nahms/dairy/downloads/dairy07/Dairy07_is_ BLV.pdf.

Brenner, J., M. Van-Haam, D. Savir, and Z. Trainin. 1989. The implication of BLV infection in the productivity, reproductive capacity and survival rate of a dairy cow. Vet. Immunol. Immunopathol. 22:299-305.

Da, Y., R. D. Shanks, J. A. Steward, and H. A. Lewin. 1993. Milk and fat yields decline in bovine leukemia virus-infected Holstein cattle with persistent lymphocytosis. Proc. Natl. Acad. Sci. USA 90:6538-6541.

Huber, N. L., R. F. DiGiacomo, J. F. Evermann, and E. Studer. 1981. Bovine leukemia virus infection in a large Holstein herd: Prospective comparison of production and reproductive performance in antibody-negative and antibody-positive cows. Am. J. Vet. Res. 42:1477-1481.

Ott, S. L., R. Johnson, and S. J. Wells. 2003. Association between bovine-leukosis virus seroprevalence and herd-level productivity on US dairy farms. Prev. Vet. Med. 61:249-262.

Pollari, F. L., V. L. Wangsuphachart, R. F. DiGiacomo, and J. F. Evermann. 1992. Effects of bovine leukemia virus infection on production and reproduction in dairy cattle. Can. J. Vet. Res. $56: 289-295$.

Quist, M. A., S. J. LeBlanc, K. J. Hand, D. Lazenby, F. Miglior, and D. F. Kelton. 2007. Agreement of predicted 305-day milk yields relative to actual 305-day milk weight yields. J. Dairy Sci. 90:4684-4692.

Reed, V. I. 1981. Enzootic bovine leukosis. Can. Vet. J. 22:95-102.

Scott, H. M., O. Sorensen, J. T. Y. Wu, E. Y. W. Chow, K. Manninen, and J. A. VanLeeuwen. 2006. Seroprevalence of Mycobacterium avium ssp. paratuberculosis, Neospora caninum, Bovine leukemia virus, and Bovine viral diarrhea virus infection among dairy cattle and herds in Alberta and agroecological risk factors associated with seropositivity. Can. Vet. J. 47:981-991.

VanLeeuwen, J. A., A. Tiwari, J. C. Plaizier, and T. L. Whiting. 2006. Brief communication: Seroprevalence of antibodies against bovine leukemia virus, bovine viral diarrhea virus, Mycobacterium avium subspecies paratuberculosis, and Neospora caninum in beef and dairy cattle in Manitoba. Can. Vet. J. 47:783-786. 